\title{
LAWRENCE KOHLBERG E OS ANOS DE CHUMBO: DEMANDAS POR JUSTIÇA E A PROCURA PELA MORALIDADE PÓS-CONVENCIONAL
}

\author{
LAWRENCE KOHLBERG AND THE YEARS OF LEAD: DEMANDS FOR \\ JUSTICE AND THE SEARCH THROUGH POS-CONVENTIONAL MORALITY
LAWRENCE KOHLBERG Y LA AÑOS DE PLOMO: LAS DEMANDAS POR JUSTICIA $Y$ LA DEMANDA POR UNA MORALIDAD POSTCONVENCIONAL \\ Eliasaf Rodrigues de Assis $^{1}$, Kleber Tuxen Carneiro ${ }^{2}$, Maurício Bronzatto $^{3}$, Ricardo Leite de Camargo

\section{RESUMO} \\ Este ensaio dedica-se a compreender o caráter biográfico da teoria cognitivo-desenvolvimentista sobre a \\ moral de Lawrence Kohlberg (1927-1987) e o contexto histórico e social em que ele a desenvolveu. Discute, \\ também, como as investigações que originaram a teoria moral kohlberguiana foram motivadas, em parte, por \\ uma aguda procura pelo sentido de justiça. Essa procura se consolidava nos movimentos sociais de protesto, \\ em produtos culturais como música e fotojornalismo e, ainda, em pesquisas específicas sobre obediência à \\ autoridade. Os "anos de chumbo" vivenciados por Kohlberg cobrem o fim da Segunda Guerra Mundial, a \\ Guerra Fria, a repressão dos protestos pacifistas e avança até meados da década de 1970 . O ensaio propõe \\ que a busca por justiça era tanto pessoal quanto uma demanda por mudança social, em escala global, \\ contemporânea à vida e carreira acadêmica de Kohlberg. Posteriormente, ao conceber a escola como um \\ espaço privilegiado da busca por justiça e pela moralidade pós-convencional, Kohlberg aplicou suas \\ descobertas à educação.
}

PALAVRAS-CHAVE: Lawrence Kohlberg. Justiça. Moralidade pós-convencional. Anos de chumbo.

\begin{abstract}
This essay is devoted to understanding the biographical nature and the social and historical context in which Lawrence Kohlberg (1927-1987) developed his theory of cognitive development about morality, as he named it himself. It also discusses how the investigations that originated Kohlberg's moral theory were motivated, in part, by an acute search for the sense of justice. This quest was consolidated on the social movements of protest, in cultural products like music and photojournalism, and in specific research about authority obedience. The "years of lead" lived by Kohlberg covers the end of the World War II, the Cold War, the repression of pacifist protests and it reaches the mid-1970s. The essay proposes that the quest of justice was not only personal, but also due to a demand for social change on a global scale, contemporary to Kohlberg's life and academic career. Subsequently, Kohlberg applied his findings to education, conceiving the school as a privileged space for the search of justice and post-conventional morality.
\end{abstract}

KEYWORDS: Lawrence Kohlberg. Justice. Post-conventional morality. Years of lead.

\footnotetext{
${ }^{1}$ Doutorado em Educação Escolar - Universidade Estadual Paulista Júlio de Mesquita Filho (UNESP) Araraquara, SP. Brasil. Docente no Centro Universitário Padre Anchieta (UniAnchieta) - São Paulo, SP. Brasil. E-mail: eliasafassis@hotmail.com

${ }^{2}$ Doutor em Educação Escolar - Universidade Estadual Paulista Júlio de Mesquita Filho (UNESP) - Araraquara, SP. Brasil. Docente - Universidade Federal de Lavras (UFLA) - Lavras, MS. Brasil. E-mail: kleber2910@gmail.com

${ }^{3}$ Doutor em Educação Escolar - Universidade Estadual Paulista Júlio de Mesquita Filho (UNESP) - Araraquara, SP. Brasil. Professor EBTT - Instituto Federal de Educação, Ciência e Tecnologia de São Paulo, Campus Salto (IFSP) - Salto, SP. Brasil. E-mail: maub1970@ig.com.br

${ }^{4}$ Doutor em Educação - Universidade Estadual de Campinas (UNICAMP) - Campinas, SP. Brasil. Professor Livre Docente - Universidade de São Paulo (USP) Universidade de São Paulo (USP) - Escola Superior de Agricultura "Luiz de Queiroz"- São Paulo, SP. Brasil. E-mail: ricardocamargo@usp.br
}

Submetido em: 13/12/2016 - Aceito em: 27/03/2017

(C) ETD- Educação Temática Digital $\quad$ Campinas, SP $\quad$ v.20 $\quad$ n.1 $\quad$ p. 276-297 jan./mar.2018




\section{RESUMEN}

Este ensayo está dedicado a la comprensión del aspecto biográfica de la teoría del desarrollo cognitivo de moral de Lawrence Kohlberg (1927-1987) y el contexto histórico y social en el que se desarrolló. También se explica cómo las investigaciones que condujeron a la teoría moral kohlberguiana se motivaron, en parte, por una demanda aguda de sentido de la justicia. Esta demanda se ha consolidado en los movimientos sociales de protesta y en los productos culturales como la música y el fotoperiodismo, y también en la investigación específica sobre la obediencia a la autoridad. Los "años de plomo" experimentados por Kohlberg cubren el final de la Segunda Guerra Mundial, la Guerra Fría, la represión de las protestas pacifistas y los avances hasta mediados del 1970. El documento propone que la búsqueda de la justicia era a la vez personal y una demanda de el cambio social a escala global, la vida contemporánea y la carrera académica Kohlberg. Más tarde, Kohlberg aplicar sus hallazgos a la educación, concebida a la escuela como un espacio privilegiado para la búsqueda de la justicia y la moral post-convencional.

PALABRAS CLAVE: Lawrence Kohlberg. Justicia. La moral post-convencional. Años de plomo.

\section{INTRODUÇÃO}

Todo recorte preciso de uma teoria pode reduzir sua exposição. Delimitar um objeto de estudo e investigação implica a seleção de alguns conceitos e o descarte de outros. É necessário ser fiel, em termos hermenêuticos, ao autor estudado e, simultaneamente, lidar com as limitações comuns a qualquer trabalho escrito. Uma consequência desse processo é abreviar, na apresentação da teoria, o que, em muitos casos, foi o empenho de toda uma vida e carreira. Não apenas a busca acadêmica objetiva, mas também a demanda pessoal, a construção idiossincrática da pessoa que realizou a pesquisa. Uma história de vida corre o risco de passar despercebida, ser reduzida ao mínimo. Logo, dado o papel relevante que Lawrence Kohlberg ocupa nas pesquisas sobre desenvolvimento moral e também sua atuação prática na educação, faz-se necessário concordar com Linn (2002, p. 137, tradução nossa): "É impossível examinar a teoria de desenvolvimento moral de Kohlberg sem destacar seus anos de formação em um determinado tempo histórico de guerra." ${ }^{5}$

O período histórico em que Kolhberg viveu e produziu foi permeado de questionamentos. Os conflitos que chamaram sua atenção se expressavam em termos políticos, acadêmicos ou filosóficos em escala global. Pessoalmente, também, ele experimentou o que chamava de demanda por justiça (BIAGGIO, 2006). Tendo passado a adolescência em uma grande cidade americana, estando em curso a Segunda Guerra Mundial (ele nasceu em Nova lorque, em 1927), "Larry"6, assim gostava de ser chamado, vivia material e familiarmente protegido no lugar que era o "topo do mundo", segundo apregoava o hit parade da sua infância, uma tradução musical do modo como os novaiorquinos se viam à época: "Estou sentado no topo do mundo, eu estou sentado no topo do mundo/apenas rolando, apenas rolando." ${ }^{7}$ Apesar da posição social estável, a herança

\footnotetext{
${ }^{5}$ "It is impossible to examine Kohlberg's theory of moral development as detached from his formative years in a given historical war time".

"Para maiores detalhes sobre o “jovem” Kohlberg, leia-se Biaggio (2006) e também Linn (2002).

7 Verso da música de sucesso cantada na infância de Kohlberg, "I'm Sitting on Top of the World" (de Ray Henderson, Joe Young e Sam Lewis), radiodifundida na década de 30 em Nova lorque.

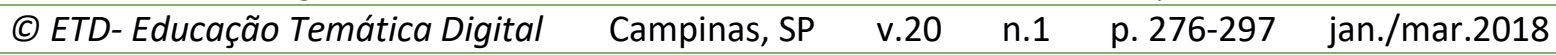


judaica e a militância no sionismo ${ }^{8}$ fizeram dele uma personagem inquieta. É o que retrata Biaggio (2006) ao descrever alguns dados biográficos de Kohlberg:

Filho de um comerciante rico, de família judaica, estudou em bons colégios particulares, como a Phillips Academy, e, terminada essa formação básica, dedicou-se ao movimento sionista. Trabalhou na Marinha Mercante, depois da Segunda Guerra Mundial, transportando refugiados judeus escondidos em navios que supostamente guardavam bananas. (BIAGGIO, 2006, p.12)

O próprio autor se preocupava em localizar a motivação de sua pesquisa entre as circunstâncias biográficas que vivenciou. Biaggio (2006), a quem os pesquisadores brasileiros devem a tradução de uma antologia com dois artigos de Kohlberg (os primeiros para o português), selecionou, como tradução indispensável, o texto "[...] Minha busca pessoal pela moralidade universal, [...] um tipo de autobiografia do autor, que se reflete na natureza do seu trabalho" (BIAGGIO, 2006, p. 80, grifo da autora). No artigo, transcrição de uma palestra de Kohlberg $^{9}$, este argumenta sobre a intricada ligação entre instâncias particulares e a escolha de um objeto de pesquisa:

\begin{abstract}
Acreditando que os interesses pessoais podem ser vistos a partir de uma perspectiva mais ampla, começarei por esquematizar brevemente como foi o início de minha preocupação com a justiça universal e o desenvolvimento do senso de justiça de um indivíduo, uma questão que me é sempre proposta, na condição de psicólogo e educador moral. (Kohlberg in BIAGGIO, 2006, p. 80)
\end{abstract}

Apesar de a busca moral pessoal ter começado cedo, Kohlberg confessava que a adolescência não foi moralmente exemplar, à maneira dos modelos de justiça que costumava citar (personagens como Gandhi e Martin Luther King). No colégio em que estudou, ele era frequentemente punido por fumar, beber e outras quebras disciplinares. Como alguns de seus colegas, não obedecia a regras que não haviam sido discutidas previamente com os envolvidos (BIAGGIO, 2006).

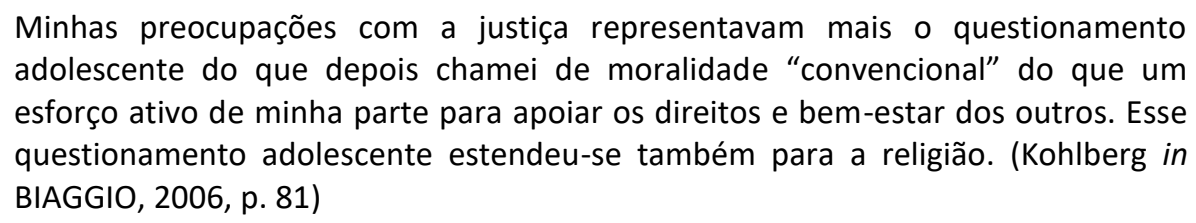

Parte dessa sua perplexidade com a moralidade convencional foi atenuada quando, sob a indicação de um professor, Kohlberg leu Os irmãos Karamázov, de Dostoiévski. A

\footnotetext{
${ }^{8}$ Movimento político-filosófico, inicialmente clandestino, que estimulava o retorno de judeus à Palestina, mesmo antes da inauguração do Estado de Israel, em 1948. O sionismo é também uma alternativa de sobrevivência ao antissemitismo.

9 "My Personal Search for Universal Morality", in L. Kuhmerker (Ed.), The Kohlberg Legacy for the Helping Professions, Birmingham, AL: R.E.P. Books, 1991.
}

(C) ETD- Educação Temática Digital $\quad$ Campinas, SP $\quad$ v.20 $\quad$ n.1 $\quad$ p. 276-297 jan./mar.2018 
experiência sorvida nesta leitura deixou raízes duradouras: Kohlberg usará a literatura em diversos momentos no desenvolvimento de sua filosofia moral. Mas as letras não foram plenamente capazes de solucionar as questões sobre justiça. Ele precisava de experiências reais. Alistando-se na marinha mercante americana assim que deixou o internato, chegou à Europa no outono de 1945, onde o cenário se compunha de cidades devastadas e histórias de genocídio.

Linn (2002) faz notar como o período pós-guerra era invadido por uma perplexidade que tomou de assalto, inclusive, os meios acadêmicos. O horror da guerra expressava também um desapontamento com a humanidade e suas produções culturais e científicas. As estatísticas do genocídio perpetrado pelos nazistas eram estarrecedoras. Para atingir seus alvos de reformulação moral (isto é, segundo seu padrão moral relativista) e criar um novo mundo, os nazistas concentraram-se em um processo altamente intricado e tecnológico de eliminação daqueles que consideravam "desviados". A operação ganhou proporções de uma joint venture, um empreendimento corporativo conjunto, multinacional, com objetivos estratégicos e logística de larga escala. Havia frentes para eliminação dos não arianos em quase todas as áreas humanas, da saúde pública, passando pelas artes plásticas e cinematográficas, até a arquitetura. O design urbanístico do 30 Reich era preparado nas pranchetas de arquitetos reconhecidos, como Albert Speer. No novo desenho do mundo, os que ficariam de fora constituíam uma massa cujo extermínio foi planejado com eficiência industrial. De acordo com a visão nazista, operada por pessoas que haviam recebido uma das melhores educações formais do século, deveriam ser eliminados, entre outros, os judeus, os homossexuais, os deficientes mentais, as testemunhas de Jeová e os ciganos. No rol dos oficiais mais obedientes do regime hitlerista, havia médicos e especialistas da saúde, pessoas muito bem formadas, inclusive na leitura da filosofia moral, o que levaria distintos psicólogos no pós-guerra a questionarem, intrigados, a baixa ou nenhuma resistência moral demonstrada pelos seguidores do nazismo. Por que não se opuseram? Afinal, o nazismo surgiu naquela que é considerada uma das mais educadas nações da Europa, terra de filósofos morais, como Immanuel Kant. E a despeito de qualquer avaliação educacional dos carrascos, restava, ainda, uma positiva abordagem sociofamiliar. Eram homens ou mulheres de família, que abraçavam os filhos, tinham animais de estimação, compunham poesias. Grandes intelectuais dedicaram-se a tentar compreender como pessoas assim eram capazes de acender os fornos das câmaras de gás. Após assistir ao julgamento de Eichmann em Jerusalém, Hannah Arendt conclui: "Foi como se naqueles últimos momentos estivesse resumindo ( $\mathrm{sic}$ ) a lição que este longo curso de maldade humana nos ensinou - a lição da temível banalidade do mal, que desafia as palavras e os pensamentos" (ARENDT, 1999, p. 250). E o que é a "banalidade do mal" a que Arendt se refere? Storino (2013) explica que a expressão é a conclusão de que o mal, que ainda hoje associamos a fanáticos ou sociopatas, pode habitar pessoas comuns e se realizar por meio delas, à medida que cometem "atos abjetos", algumas vezes sob ordens superiores que acatam sem resistir.

$\begin{array}{llllll}\text { (C) ETD-Educação Temática Digital } & \text { Campinas, SP } & \text { v.20 } & \text { n.1 } & \text { p. 276-297 } & \text { jan./mar.2018 }\end{array}$ 
A visão dos refugiados judeus do holocausto provocou em Kohlberg um rápido engajamento. Ofereceu-se como engenheiro de bordo para servir no navio Paducah, um velho quebra-gelo. Com o humor que the era peculiar, Kohlberg contou as aventuras no artigo intitulado Beds for bananas (KOHLBERG, 1948). É seu primeiro texto, não acadêmico, em que comenta como participou da marinha mercante levando clandestinos para a Palestina. Um embrião da busca pessoal por justiça, a experiência sublinhou a pauta que dominará a futura pesquisa, pois o pano de fundo da viagem marítima era o contraste entre o que é direito e o que é justo. Era direito, expresso em lei, nos tempos de Beds for bananas (1948), que judeus sionistas fossem proibidos de pisar na Palestina, então sob mandato britânico. Como algumas nações ocidentais se recusaram a recebê-los, ou exalavam antissemitismo, diversos judeus sobreviventes do holocausto não tinham para onde ir. Kohlberg, aderindo ao sionismo, concluiu que era moralmente incorreto proibir judeus, sobreviventes do holocausto em sua maioria, de voltarem a Eretz Israel, ou seja, à Palestina. Esse raciocínio, à ocasião, foi o germe de sua teoria: quando avaliamos moralmente que uma lei é injusta e danosa, é dever moral desobedecer a ela.

O Paducah era um navio para transportar refugiados ilegalmente, comprado em sigilo pela Haganá, movimento paramilitar de resistência que, após 1948, institucionalizouse como o departamento de defesa de Israel. Jovem, educado e com um promissor futuro em termos financeiros, Kohlberg deve ter surpreendido alguns dos militantes sionistas quando se ofereceu como tripulante. O navio transportaria, ocultamente, 2.000 refugiados. A marinha real britânica efetuava um bloqueio marítimo no Mediterrâneo, inspecionando navios suspeitos a caminho do litoral da Palestina. O navio de Kohlberg foi abordado. É curioso notar que um dos mais citados estudiosos da moral começou suas indagações pessoais tentando trapacear a marinha real, dizendo aos fiscais que os containers a bordo estavam carregados com bananas. Não deu certo, e toda "a carga" foi apreendida. "A marinha britânica e os fuzileiros usaram gás lacrimogênio, vapor e abriram caminho para a sala de direção e para a sala de máquinas e pararam o navio. Vários bebês morreram, embora os ingleses tivessem tentado não usar violência desnecessária" (Kohlberg in BIAGGIO, 2006, p. 92).

Enviados para campos de isolamento em terra, pelo menos alguns que sobreviviam pisavam em Israel. Mas os ingleses decidiram que eles não desembarcariam na Palestina. A maioria, inclusive Kohlberg, foi enviada para campos de concentração na Grécia. 
Eu, meus companheiros e os refugiados fomos levados para um campo de concentração em Chipre. A Hagenah ${ }^{10}$ ajudou-nos a escapar para a Palestina fornecendo-nos documentos falsos. Eu e alguns de meus companheiros de tripulação ficamos em um kibutz ou acampamento coletivo até que fosse seguro deixarmos o país com documentos falsos e pegar outro navio [...] (Kohlberg in BIAGGIO, 2006, p. 82)

De volta aos Estados Unidos, Kohlberg viu-se diante de diversas alternativas. Questionando o uso da violência, hesitava continuar sua militância sionista, ainda que para fins legítimos. Apesar do apoio ao sionismo, não se dedicou ao movimento de forma irrestrita, pois tinha dúvidas de cunho moral quanto a algumas ações. Em casa, demandas familiares punham sua identidade em crise. Sentiu-se mais incentivado quando ouviu que a Universidade de Chicago proclamava "[...] que uma vida sem questionamento não valia a pena ser vivida" (Kohlberg in BIAGGIO, 2006, p. 83). Assim, após ter resistido, matriculou-se em Psicologia clínica, em 1948. Os interesses por temas éticos o levaram a um estudo profundo da Filosofia, abrangendo Platão ${ }^{11}$, John Locke, John Stuart Mill, Thomas Jefferson e John Dewey. Deste último absorveu, além da paixão pela educação, a ideia do desenvolvimento em estágios.

\begin{abstract}
A pressuposição de que o estudo do desenvolvimento moral deve ser guiado pela filosofia moral era central para minha intuição de como focalizar esse desenvolvimento. Para que algo fosse considerado moral ou avanço evolutivo, seria necessário partir de algumas definições filosóficas, pressuposições e argumentos. Essas pressuposições estariam abertas a questionamento, à luz de achados empíricos, mas não se podia pensar que fossem isentas de valores. (Kohlberg in BIAGGIO, 2006, p. 85)
\end{abstract}

Portanto, inicialmente, foi a Filosofia, e não propriamente a Psicologia, que atraiu Kohlberg e produziu o insight de suas teorias sobre desenvolvimento moral. Ele procurava na Psicologia o que chamava de "achados empíricos" que comprovassem as suposições filosóficas. A Filosofia, em especial a clássica, estará presente em diversos de seus trabalhos, desde ensaios até artigos. Para ele, o debate filosófico ao longo da história era, por natureza, um processo de evolução da cognição, inclusive a moral, afinal, "[...] ser um filósofo significa estar preocupado com espaço, tempo, causalidade, realidade e o bem e o mal" (Kohlberg in BIAGGIO, 2006, p. 85).

Quando iniciou os estudos em Psicologia, o cenário teórico que Kohlberg encontrou no campo acadêmico era de forte polarização: Psicanálise e Behaviorismo dividiam as atenções. A falta de respostas a suas questões morais perplexas, no entanto, continuava.

\footnotetext{
${ }^{10}$ Em sua tradução, Biaggio prefere a palavra Hagenah. Comumente, em português, usa-se a transliteração Haganá.

${ }^{11}$ Quase sempre, ao dizer Platão, Kohlberg refere-se, de fato, a Sócrates. Ele chegou a mudar, à ocasião de uma republicação, o título de um ensaio: de "Education for justice: a modern statement of the Platonic (Socratic) view" (1970) para "Education for justice: a modern statement of the Socratic view" (1981).
}

(C) ETD- Educação Temática Digital Campinas, SP $\quad$ v.20 $\quad$ n.1 $\quad$ p. 276-297 jan./mar.2018 
Kohlberg ficou intrigado com a busca por justiça, e achou as tradições psicanalíticas e behavioristas muito limitantes e simplistas. Fortemente influenciado pela obra de James Mark Baldwin e um dos primeiros acadêmicos a reconhecer o trabalho pioneiro de Jean Piaget (1932/1965) sobre o julgamento moral da criança (cujos escritos em francês não eram familiares ao meio acadêmico americano), Kohlberg foi cativado pela visão da criança como um filósofo moral e a possibilidade de validade das variações ontogenéticas e da maneira como se formula o conhecimento moral. ${ }^{12}$ (LINN, 2002, p. 138, tradução nossa)

Como acentua Linn, a "descoberta" de Piaget pelos acadêmicos dos Estados Unidos é mérito de Kohlberg. Dedicando-se à leitura do epistemólogo suíço, Kohlberg sentiu-se atraído pelo método clínico piagetiano, em que o pesquisador dialogava com a criança e esta se assemelhava a um filósofo moral. Isso significava que as estruturas cognitivas poderiam ser avaliadas mediante uma entrevista. À semelhança do estudo de Piaget (1932/1994), o que importava no método clínico era permanecer atento à forma, e não propriamente ao conteúdo. Esse era um caráter inovador da pesquisa científica para Kohlberg. As teorias que conhecia no meio acadêmico se debatiam ou sobre a compreensão do irracional, por meio da Psicanálise, ou sobre a mensuração estatística do comportamento observado, como ocorria no Behaviorismo. A pesquisa piagetiana demonstrava ser possível estudar o desenvolvimento cognitivo da moralidade a partir de uma ação infantil, aparentemente trivial, como o "jogo" e as regras a que as crianças obedecem ao praticá-lo. Ao incorporar as ideias de Piaget, Kohlberg se via interessado, em especial, na "[...] busca pelos fundamentos de um desenvolvimento cognitivo da moral de princípios morais universais"13 (PICKREN; DEWSBURY; WETHEIMER, 2012, p. 282, tradução nossa). 0 interesse em Piaget também acentuou sua proximidade com a educação.

Segundo Biaggio (2006), Kohlberg, em sua tese de doutorado, em 1958, prossegue com a pesquisa feita por Piaget e investiga faixas etárias posteriores às abordadas em " $O$ juízo moral na criança" (PIAGET, 1932/1994). Ele colheu seus dados nas entrevistas em que aplicava o "dilema de Heinz" em 72 meninos brancos de Chicago. Tanto a tese quanto os futuros textos profissionais, bem como as publicações populares (ele era capaz de redigir envolventes artigos de divulgação adequados ao grande público), produziram considerável repercussão, dando origem a um novo campo de estudos.

\footnotetext{
12 “Kohlberg was intrigued by the client's quest for justice, and found the psychoanalytic and the behaviorist traditions too limiting and simplistic. Strongly influenced by the work of James Mark Baldwin and one of the first academics to recognize the pioneering work of Jean Piaget (1932/1965) on the moral judgment of the child (whose writings in French were not familiar in American academia), Kohlberg was captivated by the view of the child as a moral philosopher and the possibility of lawful ontogenetic variations in how we formulate moral knowledge".

13 "The incorporation of Piaget's ideas led Kohlberg to search for the cognitive-developmental foundations of universal moral principles".
}

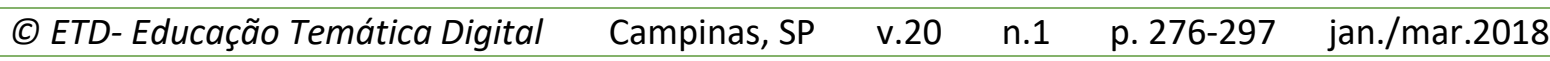


A tese de Kohlberg (1958), seus primeiros artigos profissionais (por exemplo, Kohlberg, 1963) e publicações populares (por exemplo, Kohlberg, 1968) iniciaram um novo campo de estudo, a psicologia do desenvolvimento moral. A escala de desenvolvimento moral continua sendo sua mais conhecida contribuição à psicologia moral, embora ela tenha sido aumentada em dois modelos adicionais para fornecer uma visão mais abrangente da cognição moral e desenvolvimento. ${ }^{14}$ (PICKREN; DEWSBURY; WETHEIMER, 2012, p. 282, tradução nossa)

Como os autores apontam, Kohlberg inaugurou nos Estados Unidos um novo campo de estudos, dedicado ao desenvolvimento psicológico da moral. Os estágios do desenvolvimento são sua grande contribuição ao estudo da moral. Dado o recorte deste ensaio, vamos nos deter em descrever o importante contexto, tanto histórico como pessoal, em que Kohlberg os concebeu. Essa conjuntura explicará a razão de sua abordagem ser tão abrangente (ele buscava, note-se, uma moralidade universal) e também a grande quantidade de elogios, críticas acadêmicas e atenção pública que sua pesquisa e publicações receberam.

Das críticas dirigidas a Kohlberg, interessam, aqui, em especial, as objeções que the foram feitas pela mentalidade acadêmica ou popular predominante nas décadas de 60 e 70 . Segundo ele próprio comenta, seus críticos diziam que quando "[...] empreendeu o estudo do raciocínio moral e da conduta, sua escolha de tópico o tornou o 'patinho feio' da psicologia americana" (Kohlberg in BIAGGIO, 2006, p. 84). Repudiada por acadêmicos e populares, a palavra "moral" era evitada, sendo substituída por termos mais politicamente corretos como "[...] atitude, costume, norma e valor, [...] preferidos porque pareciam mais objetivos, mais não comprometidos" (p.84). Os estudos, lançando mão da tabulação de dados estatísticos, dedicavam-se a compreender como o comportamento ocorria. Quase que invariavelmente, extrapolavam a noção de relativismo cultural, que torna aprovada em dada sociedade uma prática condenada em outra, como prova cabal de que a moral era sempre uma convenção social. Mas ao desprezar a ideia de uma moral universal, os estudiosos incidiam em um relativismo radical, segundo o qual não se pode preferir um modo de vida a outro. E, o que é ainda mais prejudicial em termos científicos, essa compreensão terminava por ignorar o processo evolutivo da moralidade humana. Kohlberg acreditava que tal tendência era um equívoco, além de desprezar o legado intelectual da filosofia clássica. Para que "[...] algo fosse considerado moral ou avanço evolutivo, seria necessário partir de algumas definições filosóficas, pressuposições e argumentos" (Kohlberg in BIAGGIO, 2006, p. 85), isto é, havia uma discussão sobre moral que antecedia o relativismo cultural. Esses fundamentos sobre moral poderiam ser debatidos, abertos a

\footnotetext{
14 “Kohlberg's dissertation (1958), early professional articles (e.g., Kohlberg, 1963), and popular publications (e.g., Kohlberg, 1968) initiated a new field of study, the psychology of moral development. His stage of moral development remains his best-known contribution to moral psychology, although he augmented it with two additional models to provide a more comprehensive view of moral cognition and development".
}

(C) ETD- Educação Temática Digital $\quad$ Campinas, SP $\quad$ v.20 $\quad$ n.1 $\quad$ p. 276-297 jan./mar.2018


questionamentos. Mas eram importantes, à luz do que chamou de "achados empíricos" (p.85).

O interesse pelos "achados empíricos" o levaria a países distantes, culturalmente diferentes, dando continuidade ao que chamava de "[...] minha busca pessoal pela moralidade universal" (Kohlberg in BIAGGIO, 2006, p. 86). Visitaria Taiwan, a China continental, Israel e a Índia, entre outros países. Até 1985, enquanto ainda era vivo, existiam 50 estudos transculturais sobre sua teoria, muitos dos quais, pesquisas longitudinais em que os sujeitos das amostras eram entrevistados desde 1955, trienalmente.

A indiferença quanto aos estudos da moral não teve vida longa. Dois anos depois que Kohlberg se doutorou, o holocausto voltou a se tornar uma discussão mundial. Adolf Eichmann foi sequestrado por forças especiais israelenses em Buenos Aires, onde vivia disfarçado, e levado a Jerusalém para julgamento. Hannah Arendt, filósofa alemã de origem judaica, testemunhou todo o processo jurídico, dos depoimentos até a execução de Eichmann, e publicou artigos de suas impressões na revista New Yorker ${ }^{15}$. Discípula de Heidegger (a quem criticou, por ter se associado aos nazistas), Hannah chegou a ser presa em um campo de isolamento na França, enquanto fugia do regime hitlerista. Apátrida durante muitos anos, era uma professora renomada, autora de uma obra filosófica definitiva: "As origens do totalitarismo", publicada em 1951. Esperava-se que, com esse histórico, Hannah Arendt realizasse a costumeira retratação dos criminosos nazistas como monstros desumanos. Mas indo além de uma cobertura jornalística, descreveu o caminho do carrasco nazista, do tribunal ao cadafalso. Em todo tempo, notava, ele se comportava com a racionalidade e serenidade de um funcionário administrativo. Eichmann não cometera crimes hediondos tomado por uma paixão ideológica. Ele não se parecia com um vilão psicótico. Era, antes, um homem comum, semelhante a outros de outras nações, que obedecia a resoluções fundamentadas nas leis de seu tempo e país. Um exemplo de cidadania, que se empenhava em seu trabalho sem questionar. Pontuando o texto com ensaios filosóficos sobre a natureza humana, Arendt atraiu críticas exasperadas daqueles que esperavam um relatório maniqueísta distinguindo claramente heróis e vilões. Ela lidaria com as críticas até o fim da vida. Mas os artigos e livros que escreveu sobre o tema atraíram a atenção de muitos intelectuais, dentre eles vários estudiosos da moral. Seus relatos são detalhados e acompanhados por observações e sínteses condensadas em expressões como "banalidade do mal". Novamente, os criminosos de guerra se assemelhavam às pessoas comuns, educadas e de boa família. Eles não se responsabilizavam pelo que fizeram, pois estavam meramente cumprindo ordens. Kohlberg ficou ainda mais perplexo com essa descrição minudenciada e cotidiana dos hitleristas. Ou, apropriando-se de um adjetivo de

\footnotetext{
${ }^{15}$ Estes artigos comporão Eichmann em Jerusalém, publicado como livro a primeira vez em 1964. É o que ela mesma comenta na nota introdutória do livro.
}

(C) ETD- Educação Temática Digital $\quad$ Campinas, SP $\quad$ v.20 $\quad$ n.1 $\quad$ p. 276-297 jan./mar.2018


Linn (2002), ele recomeçou suas investigações "abismado"16 (LINN, 2002, p. 137) com o relativismo moral defendido pelos nazistas. A questão que se punha era a seguinte: se os valores morais são relativos, os nazistas podiam ser julgados e condenados por suas atrocidades? Até que ponto as pessoas podem cumprir uma ordem sem questionar? Como responsabilizar moralmente quem deixou de resistir a uma ordem injusta?

Tanto o julgamento de Eichmann, cabalmente televisionado ${ }^{17}$, como os artigos de Hannah Arendt, fizeram com que as questões morais tomassem de assalto o meio acadêmico. Stanley Milgram, tendo como objetivo compreender a obediência cega praticada por nazistas como Eichmann, realizou o teste que publicou em outubro de 1963 no artigo "Behavioral Study of obedience" (MILGRAM, 1963) ${ }^{18}$. Os resultados eram estarrecedores: as pessoas não costumam questionar ordens, mesmo as que normalmente considerariam injustas por infligirem sofrimento a outros. Milgram publicou sua pesquisa em 1963, um momento oportuno, pois o julgamento de Eichmann ainda era discutido. Seu conhecido teste consistia em um homem de jaleco, que nem ao menos se identificava como cientista, instruindo voluntários a apertarem um botão que provocava choques elétricos em outra pessoa instalada numa sala não visível. A voltagem era progressiva, e a "falsa máquina" de choque tinha um painel, com um medidor de 15 a 450 volts e avisos como "perigo" e "choque extremo". O choque, de fato, não ocorria, pois a pretensa vítima era, na verdade, um dos pesquisadores, que simulava estar sendo eletrocutado. Mas os voluntários não sabiam disso. Fora-lhes dito que a vítima era também um voluntário disposto a receber choques, à guisa de reforço negativo, sempre que errasse as respostas a perguntas de um teste sobre memória feitas através de um microfone. Assim, os voluntários, no papel de examinadores, apertavam o botão conforme estipulado, mesmo ouvindo os gritos de dor oriundos da outra sala. Embora um potenciômetro no painel alertasse que a voltagem poderia ser fatal, foram poucos os sujeitos da pesquisa a oporem alguma objeção ${ }^{19}$. Os experimentos de Milgram (1963-1974) demonstravam como a resistência moral diante de uma ordem desumana é mínima. E não eram apenas os nazistas. Quando a guerra no sudeste asiático atingiu o ponto máximo, oficiais americanos apresentaram comportamento semelhante ao atacarem populações civis com bombas incendiárias.

\footnotetext{
${ }^{16}$ A autora usa o termo inglês "puzzled", algo entre "chateado", "intrigado por questões" ou "despedaçado".

${ }^{17}$ Disponível, entre outros endereços, em https://www.youtube.com/watch?v=aVOXYMUW4qo. Acesso em 15 abr. 2016.

${ }^{18}$ A referência mais citada é a do livro Obedience to authority: an experimental view, lançado em 1974, também incluída na bibliografia deste artigo. O livro ampliará a discussão do artigo, publicado em 1963. Graças à sua pesquisa, Milgram recebeu o prêmio anual de 1964 em Psicologia Social da American Association for the Advancement of Science.

19 Há uma descrição detalhada do experimento (que, oficialmente, só terá os nomes dos voluntários publicados em 2075) no livro da psicóloga Lauren Slater, “Mente e Cérebro” (SLATER, 2004, pp. 45-81).
}

(C) ETD- Educação Temática Digital $\quad$ Campinas, SP $\quad$ v.20 $\quad$ n.1 $\quad$ p. 276-297 jan./mar.2018 
Relatos de câmaras de gás e utilização de napalm concorriam em uma escala de horrores. Apesar dessas descrições desanimadoras quanto à moral humana, e talvez até motivadas por ela, uma demanda planetária por justiça estava ocorrendo. Fotografias do período (SULLIVAN, 2003), como Napalm Strike ${ }^{20}$ (de Nick Ut, publicada em 1973), podem ilustrar a mobilização. Nesse registro, uma criança vietnamita corre nua, o corpo queimado por um bombardeio com napalm que errou o alvo e atingiu uma aldeia. Fotojornalismo, músicas de protesto e documentários causavam aguda inquietude. E poderiam embasar uma reflexão sobre o poder da imagem no que Kohlberg (1981) chamou de "emoção moral". Na tentativa de contextualizar vida e carreira de Kohlberg, a foto de Bernie Boston, "Flower Power"121, idem de 1967, também retrata um momento inusitado. No protesto contra a guerra do Vietnã, pacifistas que se aproximavam do Pentágono foram barrados por soldados apontando fuzis. Um dos manifestantes, ao que tudo indica de modo espontâneo, calmamente inseriu cravos nos canos das armas". O livro infantil "Tistu, o menino do dedo verde" (DRUON, 2008) ${ }^{23}$ pode ter servido de inspiração. Mas nunca se saberá, pois ninguém declarou, com certeza, quem era o manifestante. Publicada nos principais jornais do mundo, quase em tempo real (as fotos eram transmitidas por rádio entre agências jornalísticas estrangeiras), a fotografia inspirou até canções brasileiras: “[...] ainda fazem da flor seu mais forte refrão, e acreditam nas flores vencendo o canhão [...] os amores na mente, as flores no chão, a certeza na frente, a história na mão" (VANDRÉ, 1968).

O "flower power" das manifestações pacifistas influenciaram o imaginário do período. Os manifestantes foram comumente associados à ingenuidade, vida simples, paz e não violência. $E$, é claro, à desobediência civil em prol de uma justiça acima das leis. Esses enfrentamentos, vale lembrar, não ocorriam unicamente nas nações capitalistas, mas também nos países situados atrás da chamada "Cortina de Ferro". O martírio voluntário e singelo era retratado, como na foto emblemática da Primavera de Praga, "Bratslava" ${ }^{24}$, de 1967, em que, de peito aberto, um homem enfrenta um tanque.

Ventos de mudança varriam o mundo. As questões morais se apresentavam em várias frentes: havia uma revolução sexual em andamento, contestando valores em voga. O papel da mulher, no sexo, em casa ou no trabalho, era amplamente discutido. E também as diferentes confissões religiosas do Ocidente sofriam revisões: os protestantes tradicionais

\footnotetext{
${ }^{20}$ Napalm Strike, de Nick Ut, 1973. In: 100 photographs that changed the world, p. 135. Também disponível em: http://www.artnet.com/artists/nick-ut/past-auction-results, Acesso em 25 nov. 2016.

${ }^{21}$ Flower power, de Bernie Boston, 1967. In: 100 photographs that changed the world, p. 140. Disponível em: http://www.famouspictures.org/flower-power/. Acesso em 25 nov. 2016. (O jornal em que Bernie Boston trabalhava rejeitou a foto, que mais tarde concorreu ao prêmio Pulitzer.)

${ }^{22} \mathrm{Na}$ "linguagem das flores", os cravos brancos simbolizam a inocência.

${ }^{23}$ Lançado em francês em 1957, traduzido para o inglês em 1958. Foi traduzido para o português por Dom Marcos Barbosa e encontra-se, na data deste artigo, na 57a edição.

${ }^{24}$ Disponível em https://iconicphotos.wordpress.com/2009/07/01/the-end-of-the-prague-spring/. Acesso em 25 nov. 2016
} 
viam, com espanto, o crescimento do Jesus people movement, em que um contingente crescente de jovens ressignificava sua fé cristã em um estilo de vida que aderia aos valores pacifistas e anticonsumistas da contracultura. Em outras palavras: sincretizavam valores evangélicos ao modo de vida dos hippies. Templos esvaziavam-se na Europa e se tornavam verdadeiras escolas de política na América Latina, onde a teologia da libertação ${ }^{25}$ fazia uma releitura dos ensinamentos de Jesus Cristo em uma ótica que criticava as injustiças econômicas, políticas ou sociais. Os direitos civis dos negros americanos eram debatidos, com reflexos que se espraiavam para os que sofriam discriminações em outros países. Miriam Makeba, artista sul-africana, após comentar as más condições vividas pelos negros em seu país, teve a nacionalidade cassada e tornou-se apátrida. No Brasil, a lei Afonso Arinos, de 1951, mostrava-se ineficiente ao considerar atos racistas apenas uma contravenção penal ${ }^{26}$, o que equivalia a não punir ninguém. Encorajado pelos movimentos para os direitos civis dos negros americanos, o incipiente movimento negro brasileiro fazia suas reivindicações e representações, em especial na música ${ }^{27}$.

Por canções, discursos ou fotos jornalísticas, produzia-se um engajamento de resistência moral em diversas partes do mundo. Ao experimentar alguma dessas obras, o espectador via-se compelido a elaborar um juízo, avaliar valores. Esse estado de despertamento, essa emoção moral vemos antecipados nos seguintes versos de Drummond: "Os camaradas não disseram que havia uma guerra e era necessário trazer fogo e alimento. Sinto-me disperso, anterior a fronteiras, humildemente vos peço que me perdoeis"28 (ANDRADE, 2012, p. 9). Sentir-se "disperso", "anterior a fronteiras" assemelhase ao estado mobilizador que a teoria kohlberguiana chama de emoção trágica (KOHLBERG, 1981), um gatilho que leva o sujeito a refletir sobre questões morais e elaborar juízos de valor mais elevados.

Academicamente, era um tempo de metodologias distintas. O Behaviorismo fazia uso de instrumentos eletrônicos sofisticados em suas pesquisas (BIAGGIO, 2006). Em outra ponta, a pesquisa mais low-tech de todas, a leitura e o diálogo, era o método utilizado. Estudiosos retornavam à mais antiga das investigações: o debruçar-se sobre as obras da

\footnotetext{
${ }^{25}$ Foi o padre peruano Gustavo Gutiérrez quem cunhou o termo “teologia da libertação", em 1971. O movimento, no entanto, já se propalava nos anos 50 e 60, encorajado pelas discussões quanto ao posicionamento dos países do 3 o mundo no cenário geopolítico de então. Para uma descrição mais detalhada do movimento e de suas perspectivas, leia-se o excelente texto de Leonardo Boff, "Quarenta anos da teologia da libertação" (BOFF, 2011). Disponível em: http://leonardoboff.wordpress.com/2011/08/09/quarenta-anosda-teologia-da-libertacao/. Acesso em 10 mai. 2014.

${ }^{26}$ Apenas com a Constituição Federal de 1988 e a subsequente lei no 7716, de 05/01/1989, o racismo tornouse um crime inafiançável.

${ }^{27}$ Em 1966, Ronaldo Bôscoli e Wilson Simonal compunham, e este último interpretava "Tributo a Martin Luther King" na entrega do Troféu “Roquete Pinto", ao vivo, antes de sua liberação pela censura.

28 "Sentimento do mundo" foi publicado em 1940. Ilustra a perplexidade dos anos de chumbo, mas lhe é cronologicamente anterior.
}

(C) ETD- Educação Temática Digital Campinas, SP $\quad$ v.20 $\quad$ n.1 $\quad$ p. 276-297 jan./mar.2018 
Filosofia clássica. Kohlberg deu tamanha atenção à Filosofia, que se pode dizer que seu trabalho tem três grandes áreas abrangidas: a Psicologia, a Educação e a Filosofia. Ao estabelecer áreas tão amplas, atraiu a atenção de muitos pesquisadores e, de igual modo, extenso escrutínio crítico, como já visto.

Em 1968, foi contratado pela universidade de Harvard, onde permaneceu até sua morte (1987). Amável e acessível, as descrições sobre ele correspondem ao que se espera de um professor carismático: "Todos que o conheciam se referem a ele como brilhante, inquieto, afetuoso, distraído, desorganizado, genial, sempre pronto a ouvir e ajudar um aluno com problemas pessoais" (BIAGGIO, 2006, p. 12).

Em Harvard, sua obra ganha ampla notoriedade. Autores de língua inglesa, ambientados com todo o conjunto da obra de Kohlberg e sua influência sobre o conceito hodierno de senso de justiça na sociedade, compreendem que ela representa um fundamento incontornável, pedagogicamente útil, indispensável para a compreensão do fenômeno da moralidade. Kohlberg é respeitado por sua pesquisa inovadora, intervenções na educação e prevenção das causas da delinquência.

\section{ESTÁGIO PÓS-CONVENCIONAL E RESISTÊNCIA MORAL}

Além dos estágios do desenvolvimento moral, foi a proposição de um estágio pósconvencional o que mais chamou a atenção na teoria kohlberguiana. Os "anos de chumbo" eram aqueles em que uma demanda por justiça tomava a sociedade. Diante de tantos exemplos de bons cidadãos agindo obedientemente sem questionar ordens e praticando atos desumanos, uma nova perspectiva se colocava. Haveria uma justiça além da cidadania expressa nas leis? Tal justiça, se compreendida, produziria uma resistência moral às leis injustas? Como essa resistência funcionaria? Linn (2002) explica: "O resistente moral ideal adota uma 'prévia para a sociedade', ou ponto de vista pós-convencional em que tenha conhecimento dos valores e direitos antes dos vínculos sociais e contratos" ${ }^{29}$ (LINN, 2002, p. 137, tradução nossa).

Essa perspectiva "prévia para a sociedade" é uma compreensão de como determinadas leis e valores não são eternos e irremovíveis. Compreender a sociedade de maneira prévia é observá-la em um quadro panorâmico em que fique claro que determinadas leis, costumes, perfis de caráter desejáveis e etiquetas foram socialmente construídos por meio de "vínculos sociais e contratos". É através do pacto social que uma sociedade convenciona suas leis e as relações que a regem. Em uma perspectiva da filosofia jurídica, num recorte que observe especificamente as teorias contratualistas, o pacto social ocorre em um momento em que a humanidade abandona seu "estado natural" e se

\footnotetext{
${ }^{29}$ "The ideal moral resister adopts a "prior to society" or post conventional standpoint from which he is aware of the values and rights prior to the social attachments and contracts".

$\begin{array}{llllll}\text { (C) ETD-Educação Temática Digital } & \text { Campinas, SP } & \text { v.20 } & \text { n.1 } & \text { p. 276-297 } & \text { jan./mar.2018 }\end{array}$
} 
submete a um poder externo (o Estado ou as leis) que passará a governá-la. É óbvio que não se trata de um momento histórico específico. Não se encontrará, objetiva ou historicamente, esse instante exato em que toda a humanidade deixou seu estado de natureza e adotou um contrato social. Antes, funcionando como um construto jurídicofilosófico, o pacto social condensa a relação de uma sociedade com uma convenção social. $\mathrm{E}$ demonstra como essa convenção é benéfica para a manutenção da paz e da prosperidade. Temporariamente. O que Kohlberg faz notar é que as convenções obedecem a uma função em seu tempo, mas por vezes precisam ser atualizadas, apontadas para um princípio maior de justiça. O "resistente moral" é aquele que percebe que uma determinada lei é injusta ou ultrapassou seu tempo de vida útil. Resistir moralmente é, portanto, demonstrar como determinadas leis ou regras sociais, ainda que possam ter atendido ao conceito de justiça em algum tempo anterior, atingiram no presente um estado perecível e já não corroboram a justiça. Precisam ser discutidas e atualizadas, alinhando-se àquilo que Montesquieu (2008) chamava "O espírito das leis". A moralidade pós-convencional, portanto, observa a sociedade com uma visão abrangente, não apenas ligada ao espaço cronológico de sua existência. Sobre isso, Linn comenta:

Desse ponto de vista, a tese de Kohlberg (1984) implica que o resistente moral é capaz de escolher entre direitos e deveres conflitantes, sem quaisquer limitações pessoais ou da sociedade. Esta perspectiva individualista é a marca da autonomia moral e maturidade moral. ${ }^{30}$ (LINN, 2002, p. 137, tradução nossa)

O resistente moral é individualista, no sentido positivo apontado por Linn, pois busca refletir moralmente e não apenas acatar a imposição do grupo ou a ossificação do contrato social, como se este fosse eterno (LINN, 1996). Soldados marcham, isto é, marcam seus passos de forma autômata, sem necessitar refletir. Já o resistente moral não marcha, mas caminha, pois, como disse alguém, "[...] a menos que estejamos marchando, cada pessoa caminha à sua maneira" (BLOOM, 2001, p. 15). Essa caminhada, ou atitude pósconvencional, é a resistência moral diante de valores convencionais. Tais valores podem ser leis ou imposições culturais. Podem ser impostos pela tradição, pelo Estado ou pelos valores de uma sociedade dominada pelo mercado. O que os configura como um momento que demanda uma moralidade superior é a necessidade de escolher entre direitos e deveres conflitantes. E nem tudo o que é direito é necessariamente justo. Uma atitude pósconvencional mostra-se insatisfeita com o juízo moral predominante em seu tempo.

\footnotetext{
${ }^{30}$ From this vantage point Kohlberg (1984) thesis implies that moral resistant is able to choose between conflicting rights and duties without any personal and society constraints. This individualistic outlook is the hallmark of moral autonomy and moral maturity.
}

(C) ETD- Educação Temática Digital $\quad$ Campinas, SP $\quad$ v.20 $\quad$ n.1 $\quad$ p. 276-297 jan./mar.2018 


\section{CONCLUSÕES E QUESTÕES PERTINENTES}

As investigações que originaram a teoria moral kohlberguiana foram motivadas, em parte, por uma aguda procura pelo sentido de justiça. Essa busca por justiça era tanto pessoal quanto uma demanda por mudança social em escala global. Resta saber: como, em suas pesquisas sobre moral, Kohlberg decidiu dedicar-se à educação?

A questão tem seu mérito, pois os estudos de Kohlberg até então apresentados são abrangentes e empíricos, mas as aplicações não foram discutidas. Por isso, é necessário notar como ele optou por aplicar suas descobertas na educação. A decisão derivou-se dos teóricos que leu. As arguições filosóficas de Kohlberg o conduziram a autores clássicos, como Sócrates ou os dramaturgos trágicos. Mas estenderam-se também, ganhando refinamento, aos epistemólogos do início da Filosofia moderna (isto é, aquela inaugurada depois da Filosofia medieval e escolástica) e chegaram aos pensadores da epistemologia do século XX. Ele pôde resumir, em um parágrafo, os estudiosos cognitivos que considerou ao formular sua teoria:

Tal filosofia e psicologia eu chamo de "cognitivo-desenvolvimentista" (Kohlberg, 1969). Ela nasceu no idealismo hegeliano alemão, mas tornou-se naturalista e científica na América com John Dewey, William James e James Mark Baldwin; na Rússia, com Vygotsky; e na Suíça, com Piaget. ${ }^{31}$ (KOHLBERG, 1981, p. 378, tradução nossa)

Destes epistemólogos Kohlberg aprendeu sobre a cognição humana e como ela se desenvolve em estágios invariantes. Dedicando-se, em especial, ao desenvolvimento moral, alinhou-se a Piaget e suas contribuições em "O juízo moral na criança" (PIAGET, 1932/1994). Essa abordagem "cognitivo-desenvolvimentista" é, como se notou, uma explicação bem diferente daquela fornecida pela Psicanálise freudiana ou pelo Comportamentalismo. Ela difere dessas duas últimas, de forma geral, na ênfase que dá à predominância da intelecção no desenvolvimento das estruturas de juízo moral. Ao mesmo tempo, Kohlberg não desprezava a emoção. Por esse motivo, ele pôde compreender como a arte condensava aspectos de razão e emoção moral. Foi o trabalho de Dewey, "Arte como experiência" (DEWEY, 2010), que o encorajou a pesquisar mais, tanto a respeito da Psicologia da arte como também sobre a Educação:

\footnotetext{
31 "Such a philosophy and psychology I call "cognitive-developmental" (Kohlberg, 1969). It was born in Hegelian German idealism but became naturalistic and scientific in America with John Dewey, William James, and James Mark Baldwin, in Russia with Vygotsky, and in Switzerland with Piaget".
}

(C) ETD-Educação Temática Digital $\quad$ Campinas, SP $\quad$ v.20 $\quad$ n.1 $\quad$ p. 276-297 jan./mar.2018 
Sua melhor declaração como uma filosofia geral e psicologia da arte vem na [obra] de Dewey, "Arte como experiência" (1937). Ao contrário do freudismo, a psicologia do desenvolvimento sublinha como as estruturas mentais são universais ou formas que se desenvolvem através de estágios invariantes. Estas estruturas entram em posições de conflito ou contradição umas com as outras, e o conflito dessas formas e sua integração (como conflitos entre forças emocionais "hidráulicas") são a alma da arte da tragédia. ${ }^{32}$ (KOHLBERG, 1981, p. 378, tradução nossa)

A inspiração que Kohlberg recebeu de Dewey não equivale a um engajamento com a filosofia deweyana. Mas quando se pensa em como Dewey valorizava a autonomia, a participação e a crítica do aluno no processo educacional, pode-se ter uma ideia do que atraía Kohlberg. Dewey repudiava o automatismo e promovia o que chamava de "experiência singular" (DEWEY, 2010), um estado intelectual e afetivo ativo por parte do aluno, muito parecido com a emoção moral. Essa experiência singular era também uma forma de estética, de desfrute artístico. As perguntas, a participação ativa e a apreciação eram indispensáveis, segundo Dewey, para o aprendizado. Envolver-se em Educação era uma oportunidade de intervenção prática que não podia ser desprezada por Kohlberg. A teoria de John Dewey fez Kohlberg formular duas conjecturas: a primeira era que o trabalho nas escolas possibilitava tal refinamento de sua teoria do desenvolvimento moral como nem a arguição filosófica ou os "achados empíricos" seriam capazes. Kohlberg concluiu que "[...] não se pode desenvolver uma teoria sobre a construção de pontes aplicando pesquisa pura" (Kohlberg in BIAGGIO, 2006, p. 88). Isto é, a prática é indispensável para a sincronia fina de uma teoria científica. E a educação é majoritariamente uma prática, e não propriamente uma disciplina. A segunda conjectura de Dewey era que qualquer teoria da Educação só é validada por uma participação orgânica, interativa entre alunado, professorado, comunidade adjacente e quaisquer outros atores envolvidos no cenário escolar.

A chance para o refinamento teórico desejado por Kohlberg surgiu quando Moshe M. Blatt, um educador na Jewish Sunday School, propôs adaptar suas histórias de dilemas morais em um currículo educacional que promovesse o progresso do raciocínio moral dos alunos. O próprio Kohlberg declararia, mais tarde, que inicialmente a ideia não lhe pareceu uma estratégia tão prática: "Eu estava cético quanto à proposta de discussão verbal de dilemas puramente hipotéticos de Blatt levar a uma mudança genuína dos estágios" (KOHLBERG, 1978, p. 3, tradução nossa) ${ }^{33}$. Berkowitz e Gibbs (1985) ressaltam como as discussões, com evidente caráter "socrático", envolvendo os alunos na ponderação e

\footnotetext{
32 “Its best statement as a general philosophy and psychology of art comes in Dewey's art as experience (1937). Unlike Freudianism, developmental psychology stresses universal mental structures or forms that develop through invariant stages. These structures come into positions of conflict or contradiction with one another, and the conflict these forms and their integration (rather than conflicts between hydraulic emotional forces) is the soul of art of tragedy".

33 "I was skeptical that Blatt's proposed verbal discussion of purely hypothetical dilemas lead to genuine moral stage change".
} 
discussão dos dilemas, eram estimuladas e facilitadas - um cenário que põe em evidência o quanto Kohlberg valorizava a participação do sujeito pesquisado como um filósofo moral. A experiência foi replicada em colégios públicos, e os dois pesquisadores apresentaram os resultados de seus experimentos (BLATT; KOHLBERG, 1975). Os alunos (entre 14 e 18 anos, a faixa etária da high school americana, equivalente ao ensino médio brasileiro) foram prétestados segundo o nível de julgamento moral formulado por Kohlberg. Um grupo experimental se submeteu a um programa de doze horas de discussão de dilemas morais diversos. Ao final da intervenção, novos testes foram aplicados e o grupo experimental apresentou uma evolução do pensamento moral maior do que aquela observada no grupo controle. O avanço do estágio moral foi afetuosamente batizado por Kohlberg (1978) de "efeito Blatt" 34 .

Esses resultados estimularam outros pesquisadores a implantarem programas educacionais que tivessem a clara intenção de desenvolver autonomia moral em jovens alunos. As escolas, em especial as públicas, foram compreendidas como ambientes democráticos, fruto de um esforço conjunto e igualitário de professores e estudantes:

\begin{abstract}
Dentre esses trabalhos, destacam-se as escolas secundárias alternativas Cluster (Massachusetts) e a Escola Scardale (Nova York). Nestas, Kohlberg e seus colaboradores buscaram criar ambientes democráticos nos quais alunos e professores tinham direito de opinar igualitariamente e se reuniam em pequenos e grandes grupos (através de uma espécie de assembleia geral) para discutir questões ligadas às normas escolares, atitudes individuais ou grupais, punições etc., e chegar a decisões coletivas que refletissem a vontade da maioria dos membros da "comunidade". De acordo com Biaggio (1997), alguns estudos demonstraram que o trabalho de Kohlberg foi efetivo para promover avanços na atmosfera moral das escolas durante os quatro primeiros anos de funcionamento do programa. (SAMPAIO, 2007, pp. 587-588)
\end{abstract}

No Brasil, diversos autores dedicaram-se a estudar o desenvolvimento moral, especificamente em suas interfaces com a área da Educação. Sem a pretensão de realizar uma lista completa, tarefa inexequível em um espaço restrito como este texto, são selecionados alguns exemplos.

Utilizando a sequência de níveis de Kohlberg, Lukjanenko (1995) verificou que o julgamento moral de professores influencia decisivamente as relações interindividuais estabelecidas em sala de aula. As características comuns principais encontradas para cada um dos três níveis de ambiente proporcionado foram as seguintes: os sujeitos do nível 1 (pré-convencional) centralizam e comandam todos os acontecimentos da sala de aula. Ocorrem punições e advertências. A ordem é imposta e os alunos, dependentes. Não há

\footnotetext{
${ }^{34}$ Há uma narrativa minudenciada da relação entre os pesquisadores no verbete "Blatt Effect", contido em "Moral Education: A Handbook", organizado por F. Clark Power e publicado em 2008.
}

(C) ETD- Educação Temática Digital $\quad$ Campinas, SP $\quad$ v.20 $\quad$ n.1 $\quad$ p. 276-297 jan./mar.2018


diálogos, trocas de pontos de vista nem respeito mútuo. As atividades são rotineiras, não há desafios. Frase que se repetiu nas observações: "Cada um deve tomar conta da sua vida".

Os sujeitos do nível 2 (convencional) também centralizam e dirigem todos os acontecimentos da sala de aula. Quase não ocorrem punições e advertências. O professor procura estabelecer a ordem com chamadas de atenção. Os alunos são dependentes. Há a tentativa de diálogo, mas voltada às expectativas do professor. O respeito mútuo está ausente: o professor é autoridade e cabe aos alunos obedecer. O professor explica, ensina, pergunta e responde, os alunos só ouvem. Há um compromisso do professor com o conteúdo, o tempo e a produtividade, mas as atividades não são desafiadoras. Frase que se repetiu nas observações: "Vamos lá, gente; se não, não vai dar tempo".

Os sujeitos do nível 3 (pós-convencional) centralizam tudo, porém como orientadores do trabalho. Como evitam fornecer conteúdos e processos prontos, o aluno participa. Professor e aluno falam e ouvem uns aos outros. Há diálogos, há trocas. Bem menos inflacionado por uma infinidade de regras, o ambiente, no entanto, é disciplinado. Observase um respeito mútuo nascente. O compromisso com a transmissão dos conteúdos está presente, mas há preocupação no professor em saber se os alunos estão aprendendo. As atividades são mais interessantes, e o material utilizado parece mais adequado.

De acordo com Biaggio (2006, p. 61), fica fácil deduzir que níveis mais altos de julgamento moral são essenciais à transformação social. "Somente indivíduos que tenham adquirido a capacidade crítica de questionamento do status quo e das leis vigentes são capazes de atuar como líderes e agentes da transformação social." Parece óbvio, segundo a autora, que um movimento político que vise à mudança social necessite de pessoas capazes de pensamento pós-convencional, quer dizer, de um questionamento crítico das regras que governam a sociedade existente. Como podem as pessoas resistirem à opressão, se permanecem na perspectiva da manutenção da lei e da ordem, típica de uma moralidade convencional?

Biaggio e col. (1999) aplicaram o método desenvolvido por Blatt e Kohlberg (1975) em um grupo de dezesseis adolescentes, por um semestre letivo. Os dilemas abordados, adaptados às demandas por justiça atuais, consideravam questões ecológicas. Os resultados fizeram notar como os índices de maturidade moral dos adolescentes com participação ativa na discussão evoluíram.

O pioneirismo das pesquisas de Angela Biaggio é ressaltado por autores recentes da pesquisa sobre desenvolvimento moral na educação. É o caso de Leonardo Rodrigues Sampaio, que avalia como programas de pesquisa e educação moral são perfeitamente factíveis no contexto brasileiro: 
[...] os trabalhos de Biaggio (1997), Biaggio e col. (1999) e Dias (1999) sugerem que intervenções dessa natureza podem ser prontamente adaptadas ao contexto educacional brasileiro, desde que existam algumas condições como, por exemplo, envolvimento e capacitação dos professores, organização de espaços (físicos e temporais) adequados, motivação dos alunos, integração do programa ao currículo regular e, acima de tudo, a criação de um clima democrático no qual prevaleça o respeito mútuo entre os membros da comunidade escolar. (SAMPAIO, 2007, p. 588-589)

Sampaio (2007) lamenta que os estudos de educação moral, em especial aqueles com implicações para o campo da educação, não tenham sido aproveitados no Brasil como deveriam.

Assis (2009) dedicou-se a pesquisar as relações de companheirismo moral em jovens universitários ingressantes. A pesquisa coligiu memoriais de 30 sujeitos, divididos em grupos iguais de homens e mulheres, que posteriormente foram entrevistados. Os resultados apontam para o fator decisivo da presença de um mentor, uma interação social, de cunho afetivo e quase sempre familiar, que está presente e atrelada às narrativas de evolução moral dos pesquisados. Como componente intrínseco que concede aos mentoreados a autonomia, verificou-se a admiração como energética psíquica principal para o acolhimento da educação moral. Esses resultados corroboram os de La Taille (2006), que, partindo das proposições clássicas de Jean Piaget (1932/1994), introduzem a dimensão afetiva da moralidade e localizam a motivação para o agir moral na relação entre valores morais e identidade.

Em um estudo com adolescentes, em que verificou a influência do recebimento de um atendimento magnânimo de compaixão como fator impulsionador do querer fazer moral, Bronzatto (2010) reuniu importantes indícios de que um trabalho educacional com obras clássicas do universo ficcional que tematizam as virtudes morais, a exemplo das intervenções que Kohlberg e colaboradores desenvolveram utilizando dilemas, pode constituir-se como fonte privilegiada de inspiração para a construção das representações de si morais.

\footnotetext{
Nossas escolhas para a "vida boa" não estão fadadas a um determinismo ético contemporâneo que expurgou do leque de opções os valores reconhecidamente morais. Por meio de uma ordem simbólica, podemos ter acesso a possibilidades irrealizadas do real e elegê-las como alvos de excelência que o ambiente cooperativo poderá gradualmente ir concretizando. (BRONZATTO, 2010, p. 429)
}

Há trabalhos ainda mais recentes que abordam o campo da Educação. Especialistas em desenvolvimento moral, Oliveira e Menin (2012), por exemplo, apresentam dados preliminares da pesquisa de mestrado "Escola-família: relações possíveis em projetos de educação moral em escolas públicas", finalizada em 2013 (OLIVEIRA, 2013). Os resultados divulgados fazem um curioso recorte ao analisarem as concepções dos agentes escolares

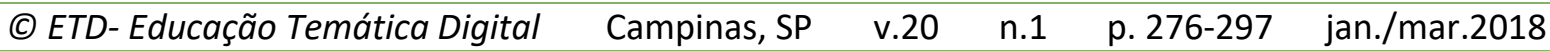


sobre o papel da família na educação moral de crianças e adolescentes. Em um levantamento bibliográfico de grande envergadura, diversas plataformas (como o Scielo, a base de dados da Capes e algumas reuniões anuais da Anped) foram usadas como fontes de pesquisas. Apesar de encontrarem bibliografia sobre educação moral e, também, sobre as relações entre escola e família, as autoras não tiveram o mesmo êxito, até a ocasião do levantamento, quando a busca era dirigida para produções que relacionassem, de forma explicita, uma e outra temática. Essa lacuna na produção do conhecimento levou-as a afirmar a necessidade de produção científica que objetive suprir a carência de pesquisas empíricas sobre educação moral e as relações entre escola e família.

Logo, as intervenções de Kohlberg e pesquisadores associados em campo escolar parecem muito apropriadas e promissoras em termos de produção de conhecimento e refinamento teórico. A escola oferece espaço e excelente oportunidade para se praticarem a democracia e a busca da justiça, bem como para se refletir sobre moral.

\section{REFERÊNCIAS}

ANDRADE, Carlos Drummond de. Sentimento do mundo. Em: Sentimento do mundo. São Paulo: Companhia das Letras, 2012.

ARENDT, Hannah. As origens do Totalitarismo. Tradução de Roberto Raposo. São Paulo: Companhia das Letras, 1989.

ARENDT, Hannah. Eichmann em Jerusalém: um relato sobre a banalidade do mal. Tradução de José Rubens Siqueira. São Paulo: Companhia das Letras, 1999.

ASSIS, Eliasaf Rodrigues de. O companheirismo moral e a formação de valores em jovens universitários. Araraquara, 2009. 185 p. Dissertação (Mestrado em Educação Escolar) Programa de Pós-Graduação em Educação - Universidade Estadual de São Paulo, 2009.

BIAGGIO, Ângela Maria Brasil; VARGAS, Gertrudes Angélica de Oliveira; MONTEIRO, Janine Kieling; SOUZA, Luciana Karine de; TESCHE, Sérgio L. Promoção de atitudes morais favoráveis através de dilemas ecológicos. Estudos de Psicologia, Natal, v. 4, n. 2, pp. 221238, 1999.

BIAGGIO, Ângela Maria Brasil. Lawrence Kholberg: ética e educação moral. 2. ed. São Paulo: Editora Moderna, 2006.

BERKOWITZ, Marvin W.; GIBBS, John C. The process of moral conflict resolution and moral development. New Directions for Child Development, v. 29, p.71-84, sep 1985.

BLATT, M. M. e KOHLBERG, L. The effects of classroom moral discussion upon children's level of moral judgment. Journal of Moral Education. Colchester, n. 4, pp.129-161,1975.

BLOOM, Harold. Como e por que ler. Tradução de José Roberto O'Shea. Rio de Janeiro: Objetiva, 2001.

(C) ETD- Educação Temática Digital Campinas, SP $\quad$ v.20 $\quad$ n.1 $\quad$ p. 276-297 jan./mar.2018 
BRONZATTO, Maurício. A ética do "desperdício": a influência da compaixão no querer fazer moral de adolescentes. 2010. 473 f. Tese (Doutorado em Educação Escolar). Faculdade de Ciências e Letras - Unesp Araraquara.

DEWEY, John. Arte Como Experiência. Tradução de Vera Ribeiro. São Paulo: Martins Fontes, 2010.

DRUON, Maurice. Tistu, o menino do dedo verde. Tradução de Marcos Barbosa. 85. ed. Rio de Janeiro: José Olympio, 2008.

KOHLBERG, Lawrence. Bed for bananas. Philadelphia: The Jewish Publication Society of America, 1948.

KOHLBERG, Lawrence. The cognitive-developmental approach to moral education. In P. Scharf (Ed.), Readings in moral education. Minneapolis: Winston Press, 1978.

KOHLBERG, Lawrence. The philosophy of moral development. San Francisco: Harper \& How Publishers, 1981.

LA TAILLE, Yves de. Moral e ética: Dimensões intelectuais e afetivas. Porto Alegre: Artmed, 2006.

LINN, Ruth. Conscience at War: The Israeli Soldier As a Moral Critic (S U N Y Series in Israeli Studies). New York: State University of New York Press, 1996.

LINN, Ruth. Mature unwed mothers: narratives of moral resistance. New York: New York [u.a.] Kluwer Academic/Plenum Publishers, 2002.

LUKJANENKO, Maria de Fátima Silveira Polesi. Um estudo sobre a relação entre o julgamento moral do professor e o ambiente escolar por ele proporcionado. 1995. $167 \mathrm{f}$. Dissertação (Mestrado em Educação). Faculdade de Educação da Universidade Estadual de Campinas SP - UNICAMP.

MILGRAM, Stanley. Behavioral Study of obedience. The Journal of Abnormal and Social Psychology, pp. 371-378, 1963.

MILGRAM, Stanley. Obedience to authority: an experimental view. New York: Harper and Row, 1974.

MONTESQUIEU, Charles de Scondat. O Espírito das Leis. Apresentação de Renato Janine Ribeiro e Tradução de Cristina Murachco. 9ạ ed. São Paulo: Saraiva, 2008.

OLIVEIRA, Alana Paula; MENIN, Maria Suzana de Stefano. Relação entre escola, família e educação moral: um levantamento bibliográfico. In: IX SEMINÁRIO DE PESQUISA EM EDUCAÇÃO DA REGIÃO SUL, 2012, Rio Grande do Sul. Anais do 9 Seminário de Pesquisa em Educação da Região Sul. Caxias do Sul: UCS, 2012.

OLIVEIRA, Alana Paula. Escola e família: relações possíveis em projetos de educação moral em escolas públicas. Presidente Prudente: 2013. 136 f. Dissertação - (Mestrado em Educação) Universidade Estadual de São Paulo.

$\begin{array}{llllll}\text { (C) ETD-Educação Temática Digital } & \text { Campinas, SP } & \text { v.20 } & \text { n.1 } & \text { p. 276-297 } & \text { jan./mar.2018 }\end{array}$


PIAGET, Jean 0 juízo moral na criança. Tradução de Elzon Lenardon. São Paulo: Summus, 1932/1994.

PICKREN, Wade E.; DEWSBURY, Donald A.; WETHEIMER, Michael. Portraits of Pioneers in Developmental Psychology. London: Psychology Press, 2012.

SAMPAIO, Leonardo Rodrigues. A psicologia e a educação moral. Psicologia Ciência e Profissão, Brasília, v. 27, n. 4, p. 584-595, dez. 2007.

SLATER, Lauren. Mente e cérebro. Tradução de Vera de Paula Assis. Rio de Janeiro: Ediouro, 2004.

STORINO, F. F. Eichmann na Paulista. Revista da Escola de Administração de Empresas da Fundação Getulio Vargas, p. 76, 2013.

SULLIVAN, Robert. 100 photographs that changed the world. New York: Life Books, Time inc. 2003.

\section{MÚSICAS:}

Henderson, R. Young, Joe e Lewis, Sam. I'm Sitting on Top of the World. New York: versão sem gravadora, 1925, radiodifusão.

Bôscoli, Ronaldo e Simonal, Wilson. Tributo a Martin Luther King. São Paulo: Odeon, 1967, disco compacto.

VANDRÉ, Geraldo. Pra não dizer que não falei das flores. São Paulo: Discos RGE-Fermata, 1979. 1 LP.

\footnotetext{
'Revisão gramatical do texto de língua portuguesa sob a responsabilidade de: Maurício Bronzatto
} 